\title{
Impact of bottom contact trawling on benthic biogeochemical cycling in the Southern Baltic Sea
}

\author{
MARY A ZELLER ${ }^{1}$, JENS KALLMEYER ${ }^{2}$, DAVID \\ CLEMENS $^{3}$, MISCHA A SCHÖNKE ${ }^{1}$, STEFAN SOMMER ${ }^{3}$ \\ AND PROF. MICHAEL E. BÖTTCHER, \\ DR.RER.NAT.HABIL. 1,4,5 \\ ${ }^{1}$ Leibniz Institute for Baltic Sea Research \\ ${ }^{2}$ GFZ German Research Centre for Geosciences, Section 3.7 \\ Geomicrobiology \\ ${ }^{3}$ GEOMAR Helmholtz Centre for Ocean Research Kiel \\ ${ }^{4}$ Marine Geochemistry, University of Greifswald \\ ${ }^{5}$ University of Rostock \\ Presenting Author: mary.zeller@io-warnemuende.de
}

Bottom contact trawling from commercial fishing activity can have profound impacts on the sea floor, as trawling gear can both resuspend the surface sediments and shift sediment to the sides of the gear, forming furrows and mounds. This disturbance can thus have profound impacts on the benthic biogeochemistry, as these surface sediments generally contain the most labile organic matter, and the porewaters can be elevated in dissolved redoxsensitive metals (Fe and Mn). Disturbance can thus mix these Feand $\mathrm{Mn}$ - rich porewaters with oxygenated bottom waters, which can reoxidize and form particles, potentially making their distribution more heterogeneous and acting as a substrate for sorption processes. As these particulate iron oxy(hydr)oxides and manganese oxides can be reduced by the sulfide produced by microbial sulfate reduction, the distribution of these phases has profound implications for the habitability of surface sediments by modifying sulfide concentrations and related toxicity for higher life. Here, we report on a research endeavor in Fehmarn Belt, an extensively fished region in the Southern Baltic Sea, Germany. Inside of this area, we collected sediment cores from a variety of sites ranging from undisturbed (due to a nearby shipwreck and boulders) to heavily trawled. From these cores we analyzed a suite of porewater parameters (including: dissolved sulfide, $\mathrm{Fe}, \mathrm{Mn}, \mathrm{SO}_{4}$, nutrients, and ${ }^{13} \mathrm{C}$-DIC), solid phase parameters (including: $\mathrm{Hg}$, TIC, $\mathrm{CNS}$, reactive $\mathrm{Fe}$, and reactive $\mathrm{Mn}$ ), as well as rates of sulfate reduction (SRR). Due to the addition of an ultra-short baseline acoustic positioning system (USBL) on our multicorer (MUC), we are able to relate these parameters not just to coarse estimates of areal trawling density, but also obtain a fine (about $1 \mathrm{~m}$ ) estimate of the MUC location in relation to specific trawl marks. Thus, we are well equipped to broaden our understanding of the impact of bottom contact trawling on benthic biogeochemical element cycling. 